Motrivivência Ano XXIII, No 36, P. 306-322 Jun./2011

doi: 10.5007/2175-8042.2011v23n36p306

\author{
A EDUCAÇÃO SOMÁTICA \\ E OS CONCEITOS DE \\ DESCONDICIONAMENTO GESTUAL, \\ AUTENTICIDADE SOMÁTICA E \\ TECNOLOGIA INTERNA
}

Débora Pereira Bolsanello'

\title{
RESUMO
}

A Educação Somática é um campo teórico-prático composto de diferentes métodos cujo eixo de atuação é o movimento do corpo como via de transformação de desequilíbrios mecânico, fisiológico, neurológico, cognitivo e/ou afetivo de uma pessoa. Apresentamos três conceitos que delineam a identidade do campo da Educação Somática e caracterizam suas propostas em aula: descondicionamento gestual, autenticidade somática e tecnologia interna. Visa-se a auto-investigação do movimento do corpo através de técnicas de desenvolvimento da propriocepção; o aprendizado de novas maneiras de mover-se que previnam lesões e o uso intencional dos mecanismos de autoregulação.

\section{Educação Somática}

Pense com o corpo todo.

Taisen Deshimaru

Entre ciência e arte, a Educação Somática é um campo teórico- prático composto de diferentes métodos cujo eixo de atuação é o movimento do corpo como via de transformação de desequilíbrios mecânico, fisiológico, neurológico, cognitivo e/ou afetivo de uma pessoa.

1 Mestre em dança pela Université du Québec à Montréal (Quebec, Canadá), fundadora de MOVIMENTO: Centro de Formação e Pesquisa em Educação Somática; bacharelado em Antropologia pela Université de Montreal e membro do CERAP (Centre d'Étude et de Recherche Appliquée en Psychopédagogie Perceptive, Universidade de Porto, Portugal. Contato: deborabolsanello@gmail.com 
Os métodos que compõem o campo foram fundados há mais de um século na Europa e na América do Norte: Técnica de Alexander, Feldenkrais, Antiginástica, Eutonia, Ginástica Holística, Continuum, Body Mind Centering, Cadeias Musculares e Articulares G.D.S., Somaritmo e certas linhas do método Pilates

A Educação Somática emerge de um processo evolutivo que se constrói sobre a base de uma pesquisa experiencial. A experiência corpórea situa-se no coração desse novo paradigma, que começa a encontrar seus títulos de nobreza nos meios universitário e acadêmico. Surgem programas universitários no Canadá (...) na Université du Québec à Montreal; em Portugal, sob minha própria iniciativa, através de um mestrado em Psicodegagogia Perceptiva, bem como no Rio de Janeiro, Brasil, com duas pós-graduações em Educação Somática da UniverCidade, sob a direção de Silvia Sotter e na Faculdade Angel Vianna. (BOIS, 2008, p.9).

A palavra soma foi reinventada por Thomas Hanna, professor do Método Feldenkrais e editor da revista Somatics, que distingue os conceitos de corpo e soma: « (...) soma é o corpo subjetivo, ou seja, o corpo percebido do ponto de vista do indivíduo. Quando um ser humano é observado de fora, por exemplo, do ponto de vista de uma $3^{\text {a }}$ pessoa, nesse caso, é o corpo que é percebido. » (2003)

O presente artigo é um prelúdio de formulação de três conceitos que delineam a identidade do campo da Educação Somática: descondicionamento gestual, autenticidade somática e tecnologia interna.

Desde 1988 tenho refletido sobre esses conceitos a partir de leituras, de experiência pessoal como aluna de diferentes professores de Educação Somática; da prática professoral junto a um público composto de fisioterapeutas, artistas, pacientes em tratamento do câncer e dependentes químicos e do papel de diretora pedagógica da Formação em Técnicas de Educação Somática, que ministro no Brasil desde 2008. A motivação de se pensar os conceitos acima vem da constatação:

Acredita-se que termos como consciência corporal, esquema corporal, esquema postural, percepção corporal (...) imagem do corpo, noção do corpo (...) não fazem parte de uma estrutura léxica coerente ou que permitam uma linguagem uniforme ou como padrão entre os profissionais que têm por objeto de 
estudo o Homem e sua motricidade. (HABIB, 2001, p. 7)

É com o objetivo de contribuir à criação de uma linguagem própria aos educadores e terapeutas que trabalham com a motricidade humana que traçamos os primeiros passos de formulação dos conceitos de descondicionamento gestual, autenticidade somática e tecnologia interna. É preciso sublinhar, porém, que cada método de Educação Somática possui princípios teóricos e estratégias pedagógicas próprias. Não nos atardaremos sobre as diferenças entre os métodos.

Antes de abordamos os conceitos, introduziremos abaixo algumas das características comuns aos métodos de Educação Somática no tocante a como o professor aborda o movimento do corpo de seus alunos no contexto das aulas.

\section{A diminuição do ritmo : $O$} professor propõe que o aluno faça os movimentos de forma mais lenta do que habitualmente ele faz a fim que possa perceber as estruturas músculo-esqueléticas implicadas quando executa o movimento. É o primeiro passo de uma tomada de consciência de como se executar um movimento de maneira justa.

2. A respiração como suporte do movimento : O professor não dita um ritmo respiratório para a execução do movimento, mas pede ao aluno que use seu próprio ritmo respiratório como suporte do movimento.

3. A interpretação da diretriz verbal: $O$ professor não demonstra os movimentos ao aluno para que ele não se torne um modelo. $\mathrm{O}$ aluno é levado a interpretar as comandas $^{2}$ segundo a percepção que tem de seu corpo, seus limites e potencial.

4. A auto-pesquisa do movimento: As comandas não dirigem o aluno à mera execução de uma seqüência de movimentos, nem a um aperfeiçoamento dessa seqüência. Trata-se de incitar o aluno a explorar, através do movimento, conexões entre partes do corpo aparentemente desconexas.

5. A auto-massagem: Através do uso de objetos auxiliares (bolas, bastões, etc), o aluno

2 "Comando" é um substantivo masculino, porém, no contexto de formulação de conceitos próprios ao campo da Educação Somática insisto em usar "comanda" como substantivo feminino para reforçar o fato de que o professor de Educação Somática não está no "comando" do exercício, mas ele faz uma encomenda ao aluno. 
é levado a massagear-se e a reativar o sistema proprioceptivo.

6. A busca do esforço justo: $O$ professor pede ao aluno que procure o tônus ótimo para realização do movimento proposto a fim de que o aluno comece a distinguir as variações de seu tônus e comece a integrar a capacidade a regular seu tônus de acordo com a situação e com o objetivo da tarefa a ser feita.

7. O alongamento fino e preciso: Uma parte dos movimentos propostos visa o alongamento de músculos da postura e tendões.

8. O aumento do vocabulário gestual: Muitos dos movimentos propostos são movimentos que não são usados no cotidiano. Esses movimentos muitas vezes causam estranheza no aluno, porém, têm por objetivo a gradual desconstrução de padrões motores inconscientes noscivos à estrutura psicofísica do individuo na medida que favorecem o aparecimento de LERs. Por outro lado, os movimentos inusitados e lúdicos formam novas conexões neuronais e o estabelecimento padrões motores mais eficazes.

9. Aprendizagem "leiga": Diferentemente da Yoga e do Tai Chi, cujas práticas são fundamentadas nos Vedas e no Taoísmo, filosofias espirituais da Índia e da China, os métodos de Educação Somática não estão associados a um sistema de crenças religiosas.

Tendo tomado contato com alguns aspectos da atuação dos profissionais de Educação Somática, passamos agora à apresentação dos conceitos de descondicionamento gestual, autenticidade somática e tecnologia interna.

\section{O descondicionamento gestual}

\author{
(...) você não aprenderá \\ nada de novo, \\ mas desaprenderá um certo \\ número de hábitos \\ adquiridos ao longo de sua vida. \\ Richard Brennan ${ }^{3}$ \\ Os diferentes métodos de \\ movimento do corpo no espaço. $\mathrm{O}$ \\ que é próprio ao campo da Educa-
} Educação Somática criaram contextos de aprendizado cujo eixo é o ção Somática é que o aluno aprende 
a sentir seus movimentos; perceber como executa-os e explorar variações em seu modo de mover-se. O aluno não é treinado para executar formas coreográficas, nem tampouco aprenderá a aperfeiçoar asanas ${ }^{4}$ ou katas ${ }^{5}$. Ilustramos essa proposta através do exemplo:

Uma colega fisioterapeuta, especialista em RPG trata de um pianista profissional cuja cifose atingiu tal grau que a deformação da coluna põe em jogo o bom funcionamento de seus sistemas respiratório e digestivo. Anos de estudo do piano sem qualquer enquadramento educacional-somático tiveram por resultado a fixação de padrões de movimento altamente performáticos a nível musical porém nocivos para a coluna do pianista. "Se eu endireitar minha coluna, não vou conseguir tocar", afirma o músico.

Casos desse tipo são muito comuns. Desde nossa infância, aprendemos a suprir nossas necessidades através de uma gama de movimentos. Aprendemos por repetição a dar respostas motoras a fim de garantir nossa sobrevivência. Aprendemos a colocar a colher na boca, a andar, a permanecer sentado diante da televisão, a permanecer de pé na fila do banco, a descascar legumes, a falar diante de uma platéia ansiosa. Movimentos que se fixam em constelações e se tornam padrões. Movimentos que cumprem a função de nos manter vivos.

O problema não está no estabelecimento de padrões de movimento. Sem eles não conseguiríamos repetir a tarefa de digitar um texto no computador mais de uma vez. Porém, problemas como o fenômeno da dor, por exemplo, aparecem quando a resposta que aprendemos a dar não é adaptada a novas circunstâncias. Se não expandirmos a rede neuronal ligada ao sentido kinestésico através do aprendizado de novas maneiras de mover-nos, ao longo de nossa vida forjaremos um vocabulário gestual restrito. É esse vocabulário gestual limitante que termina por desgastar as estruturas, como o veio de um rio que esculpe o leito por onde passa e erode as pedras.

Cada vez que o pianista lê na partitura a nota DO, ele deve apertar o DO no teclado do piano. Porém, ao passar dos anos, ele associou o movimento de apertar o DO com o movimento de levantar os ombros. Talvez ele tenha associado esses dois movimentos porque a princípio o gesto de levantar os ombros facilitava o gesto de apertar o DO. Ou talvez porque o momento da música

4 Asanas são as posturas praticadas na Yoga.

5 Katas são sequências de movimento fixas para o aprendizado de técnicas de combate e defesa. 
quando o DO se faz ouvir inspira uma certa emoção que o pianista exprime levantando os ombros. Saber exatamente o porquê de certas associações se estabelecerem pode ser esclarecedor, mas não é imprescindível para a pessoa aprender a dissociar os gestos. Anos se passam e muitos DOs são tocados. O pianista sobrecarrega continuamente a articulação dos ombros. Ele começa então a sentir dor nos ombros. Em seguida, dores lombares. Em seguida uma sensação de falta de ar, cada vez que se senta para tocar.

Uma estrutura que está sobrecarregada por seu uso repetitivo e inconsciente termina por se desgastar. Com o desgaste da estrutura se desencadeiam dor, desfonforto e perda de funcionalidade. Um quadro de dor crônica afeta o humor, a auto-estima e a vida social de uma pessoa. Reflexos e automatismos nos permitem sobreviver - física e emocionalmente. Mas estamos na Terra não para sobreviver, mas para viver. E usar todo o potencial que temos como seres humanos.

A Educação Somática aborda esse tipo de problemática investigando junto com a pessoa a maneira com a qual ela se move. No caso do pianista, a maneira com a qual ele toca piano engendrou uma série de compensações que resultam em dor e perda de funcionalidade, tal como coloca Goldfarb (1998):

Uma contratura muscular crônica significa que os músculos permanecem contraídos permanentemente. Por isso, eles não podem mais fazer seu papel primordial de se contrair para fazer os ossos se moverem. Essa contração crônica não tem por efeito somente a de restringir a liberdade de movimento de uma articulação, mas ela age também como um amortecedor, "absorvendo" o movimento ao invés de deixá-lo transmitir-se ao resto do esqueleto ${ }^{6}$.

Para executar uma mesma tarefa - pressionar a tecla DO do piano - usando um gesto livre de tensões inúteis, é preciso em primeiro lugar sentir. Sentir meu dedilhar no piano. Perceber meu corpo de um ângulo diferente daquele com o qual estou habituado: por exemplo, perceber que o gesto de tocar o DO não precisa de um esforço

6 Une raideur musculaire chronique signifie que les muscles restent contractés en permanence. De ce fait, ils ne peuvent plus jouer leur rôle primaire qui est de se contracter pour faire se mouvoir les os. Cette contraction chronique $\mathrm{n}^{\prime}$ a pas seulement pour effet de restreindre la liberté de mouvement d'une articulation, mais elle agit aussi comme un amortisseur en " absorbant " le mouvement au lieu de le laisser se transmettre au reste du squelette. (Goldfarb, 1988, pg. 51). Tradução da autora. 
muscular extra: esse gesto pode ser percebido como sendo ancorado na cintura escapular, por exemplo. Em seguida, reaprender a conectar o movimento de tocar o DO com a rotação da coxo-femoral dentro do acetábulo, sustentado pelo apoio dos pés no chão e dos ísquios na cadeira. Essas conexões permitem o que a cintura escapular possa fazer seu trabalho: sustentar o gesto de tocar o DO, que não está isolado do resto do corpo e não precisa de tanto esforço para ser realizado uma vez que se usa o suporte ósseo das cinturas pélvica e escapular.

O processo de descondicionamento gestual é um refinamento da capacidade de adaptarmos nossas respostas a diferentes circunstâncias; um processo de reorganização de nossa imagem corporal. Alexander, criador da Técnica de Alexander, formulou o conceito de Inibição a partir das observações que fazia de si próprio : "Segundo Alexander, a Inibição não é supressão, mas intenção.
Ela nos permite realizar aquilo que decidimos realizar."(Brennan, 2006, p.52) ${ }^{7}$. Trata-se de descobrir novas soluções para mover-se, que consiste em: "parar, antes de reagir instintivamente a uma dada situação" (Brennan, 2006, p.47) ${ }^{8}$

Linda Hartley explica que: "A doença, do câncer aos problemas psicóticos, pode ser vista como expressão do grau ao qual o corpo-mente é incapaz de responder, de se abandonar, de mudar (...). Essa capacidade de responder é ao mesmo tempo o suporte e a medida de nossa saúde."(Hartley, 1995, p.124-125) ${ }^{9}$

Se a atitude cifótica do pianista muda, muda também a relação de seu corpo com o piano ${ }^{10}$. A perda de referência da relação piano-corpo pode levar o pianista a perceber que «endireitando" a coluna ele não consegue mais tocar como costumava. Ele prefere então, manter a cifose do que perder o prazer de tocar ou ameaçar sua carreira de músico, caso sua performance

7 «Selon Alexander, I'Inibition n'est pás I'expression d'une supression, mais d'une intention. Elle nous permet d'accomplir ce que nous avons décidé d'accomplir. »(Brennan, 2006, p.52). Tradução da autora.

8 “(...) s'arrêter avant de reagir instinctivement à une situation donnée" (Brennan, 2006, p.47). Tradução da autora.

9 "Illness, from cancer at one end of the spectrum to psychotic disorders at the other, maybe seen as an expression of the degree to which the body-mind is unable to respond, let go, change (...) This responsiveness supports and is a measure of our health." (Traduction de I 'auteure).

10 Segundo as próprias palavras do pianista, sua relação com o meio ambiente também apresentou mudanças: "Depois das sessões com minha fisioterapeuta, comecei a perceber que eu olhava mais para as pessoas." 
seja ruim. Goldfarb, professor do método Feldenkrais, esclarece qual o papel da Educação Somática em casos como esse:

A primeira coisa que um aluno aprende é que é possível sentirse diferente. A partir disso, ele pode tornar-se consciente de sua maneira de mover-se e de que maneira ela esta atrelada aos problemas dos quais ele reclama $^{11}$. (Goldfarb, 2006, p.131)

Para contornar o estabelecimento de gestos automáticos que causam desgaste, desconforto e perda de função, o professor de Educação Somática usa estratégias pedagógicas.

O educador somático não aplica protocolos pré-estabelecidos de tratamento. É preciso escutar o que a pessoa fala sobre seu próprio desconforto e que discurso ela tem sobre seu corpo. O "mal-respirar" que a secretaria relata não é um problema respiratório. Não se trata de prescrever exercícios respiratórios. Isso equivaleria a ensinar um peixe a nadar. O educador aborda a pessoa, não o desconforto do qual ela reclama. Ele guia o aluno a observar quais partes do seu corpo se movem quando ele respira.
Ele não diz à secretaria que ela respira mal nem aponta regiões de seu corpo, colocando os bloqueios em evidência. $\mathrm{O}$ aluno é levada a tomar consciência de sua maneira de respirar atual, por exemplo. Sem julgamentos. Em seguida o professor propõe movimentos que liberam tensões inúteis que entravam a respiração fisiológica e natural.

O educador somático transmite ao aluno instrumentos a partir dos quais ele pode desenvolver respostas renovadas. Se o descondicionamento gestual reflete uma nova capacidade a responder a nível motor e/ou a nível afetivo, a ativação de uma tecnologia interna proporciona ao aluno saber como adaptar sua organização corpórea durante a execução de um dado movimento em um dado contexto de forma a não deteriorar sua estrutura física nem comprometer sua integridade psíquica. Gómez, criadora de Somaritmos, um dos mais recentes métodos de Educação Somática, usa o termo "modular" para indicar o resultado de um processo de descondicionamento gestual e uso da tecnologia interna:

Modular é passar melodicamente de um tom a outro. Geralmente se usa essa palavra em relação a sons e tons musicais.

11 « La première chose qu'apprend l'élève est qu' il est possible de se sentir différent. Cela étant, il peut devenir conscient de la manière de bouger et de la façn dont celle-ci est reliée aux troubles dont il se plaint. » (Goldfarb, 2006, p.131). Tradução da autora. 
Aqui nos referimos à capacidade de modular a atenção e os movimentos através do corpo de diversas maneiras a fim de conseguir ajustar nossos estados internos às exigências externas e vice-versa, satisfazendo assim às nossas necessidades ${ }^{12}$. (Gómez, 1997, p. 3)

Uma pessoa em processo de descondicionamento é alguém que cultiva a variedade de seu vocabulário gestual. Liberar a memória corporal de gestos que não são mais necessários para se tocar a nota DO. Limpar o corpo das impressões deixadas pelas tensas relações do dia-adia. Reconhecer as diferenças entre as situações e estar apto a escolher dentre as cores de sua paleta gestual, as que são mais adequadas para o cumprimento de uma ação.

\section{Autenticidade somática}

Sentimos que não devemos viver da mesma maneira com a qual viveram nossos ancestrais. Sentimos que devemos dar um passo além. Sabemos que esse passo será dado no escuro e que isso requer coragem. Agnès Martin
É o processo de descondicionamento que permite que a pessoa entre em contato com sua autenticidade somática. A autenticidade somática emerge de uma intimidade com nossos próprios processos internos (fisiologia, sensação, sentimento, pensamento, percepção...) e não é contraditória com a identidade sociocultural. A autenticidade somática é tal qual um vaso: fornece um container à identidade sociocutural. Somos ao mesmo tempo relação e singularidade. Sem a autenticidade somática como referência, nós seríamos apenas máscara, clã, trupe, "galera", massa. Nós nos definiríamos apenas através do pertencer a um grupo e nossa singularidade seria abortada. Sentir(-se) equivale a reconhecer sua unicidade. Goldfarb (2006, p.116) conclui: "Sentir é apreciar uma diferença, fazer uma distinção. ${ }^{13}$ »

Hoje, os centros de condicionamento e fitness vendem seus serviços com a embalagem "qualidade de vida". O culto do corpo tônico é veiculado pelas mídias representando sucesso, capacidade de performance, jovialidade, agilidade e sensualidade. O modelo de

12 Modular es pasar melodicamente de um tono a outro. Generalmente esta palabra se usa em relacion com los sonidos y tonos musicales. Aqui nos referimos a la capacidad de modular la atencion y los movimientos a través del cuerpo de diversas maneras para lograr ajustar nuestros estados internos a las exigencias externas y viceversa y asi satisfacer nuestras necesidades. (Gómez, 1997, p. 3). Tradução da autora.

13 Sentir, c'est apprécier une différence, faire une distinction. (Goldfarb, 2006, p. 116). Tradução da autora. 
corpo fabricado dentro dos centros de condicionamento faz eco com os valores da sociedade de consumo: produtividade, competitividade e rapidez. Os tipos de movimento propostos aos usuários dessas academias têm o objetivo de retardar as marcas do envelhecimento tonificando a musculatura e aumentando a capacidade cardio-vascular.

Herdeiros dos gestos de trabalhadores de fábricas que funcionam em grandes cadeias de produção, a abordagem do corpo nas academias se faz através de movimentos repetitivos que requerem o uso de partes isoladas do corpo. Por serem divorciados da consciência, esses movimentos levam a uma fixação de certas conexões neuronais. Rapidamente o piloto automático se instala: para remediar a monotonia, a pessoa leva uma revista para ler enquanto sobe escadas imaginárias, ou assiste televisão durante a corrida na esteira. Capturados pelo espelho, os praticantes vêem, mas não sentem o movimento que estão realizando. Por trás dessa fratura entre corpo e mente estão uma gama de acidentes e de lesões por esforço repetitivo. Na base desse tipo de atividade física estão situados valores normatizantes que fazem abstração da subjetividade corpórea de indivíduos. Valores normatizantes que homogenizam o corpo sob a hégide de uma mesma forma, forma essa que é atingida através do consumo de bens e serviços de toda uma industria do fitness. A singularidade do sentir-seu-corpo cede seu lugar ao querer-parecer com as formas dos corpos representados na mídia.

De quem é meu corpo ? Multifacetado, desvinculado do sujeito, o corpo contemporâneo luta por sobreviver em meio a ideais inatingíveis de beleza; à comercialização de sua imagem; à sua "virtualização"; às exigências de produtividade; à sua hipersexualização; à sua submissão à autoridade médica; à medicalização abusiva e à saturação de imagens de violência. Então, de quem é meu corpo afinal?

Cada organismo tem um padrão único de movimento. Esse padrão de movimento é gracioso porque é a expressão do eu natural, do eu inato. Ele tem uma autoridade própria, uma verdade própria. ${ }^{14}$ (Keleman, 1975, p.28)

A autencidade somática é um valor que se reflete em gentileza para com o outro e cuidado com o

14 Every organism has a unique pattern of movement. That pattern of movement is graceful because it is an expression of its natural self, is innate self. It has its own autority, its own truth. (Keleman, 1975, p.28). Tradução da autora. 
meio ambiente. Na ótica da Educação Somática, autenticidade não significa distinguir-se do mundo pois "é através do mundo que se tem consciência do próprio corpo" (HABIB, 2001, p. 123). Autenticidade é singularização, o corpo não como maquina, mas como experiência. $\mathrm{O}$ corpo como estado de disponibilidade, onde podemos desenvolver uma tecnologia interna.

\section{A tecnologia interna}

Vida é o que acontece a você enquanto você está ocupado fazendo outros planos. John Lennon

Desde a Revolução Industrial, testemunhamos o estabelecimento de um modo de vida ancorado na capacidade de produção. É claro que a inventividade é inerente ao Homem. Mas o que observamos hoje é a produtividade desenfreada e dissociada de valores humanos, divorciada do cuidado, na medida em que vale mais a quantidade de tarefas realizadas do que a qualidade de execução dessas tarefas.

A Educação Somática é um dos antídotos para a atividade compulsiva, colocando o foco de atenção no como se realiza uma ação. O como ao qual me refiro não é o de saber apertar um botão de uma câmera para regular o foco. $\mathrm{O}$ como, visto pela ótica da tecnologia interna é o saber alinhar meu corpo junto com a câmera para tirar um foto sem ficar com um torcicolo, por exemplo. Esse saber é muito útil sobretudo se eu ganho meu pão como fotografo profissional. O corpo tornase instumento. Sei como utiliza-lo sem abusar de seus limites.

(...) o espaço não existiria se o corpo não existisse (...) Isto porque, é por meio do corpo como potencial cinético de um numero de ações familiares, ou seja, do corpo como projeto motor, como intencionalidade, que este se instala no meio circundante. (HABIB, 2001, p. 132-133)

Se sou garçonete de um restaurante, de que modo seguro as bandejas pesadas para servir os clientes para evitar dores na lombar? Se sou bancário, será que continuo a respirar cada vez que conto cédulas? Ou sera que diminuo minha amplitude respiratória ao contar dinheiro, anestesiando meu sentimento de descontentamento? Se sou funcionário de uma empresa, como estou sentado diante de meu computador? Será que eu é que me adapto ao computador ou ele a mim?

Essas pequenezas do diaa-dia se acumulam em nosso corpo. As tarefas de sobrevivência são repetidas muitas vez por dia a cada dia durante anos e anos. É na noção 
de cuidado que reside uma das chaves para transformar os condicionamentos psico-fisicos que nos permitem sobreviver.

O grande desafio para o ser humano é combinar trabalho com cuidado (...) o trabalho como busca frenética de eficácia, como afã nervoso de produção e ânsia incontida de subjugação da Terra. Os últimos séculos, entretanto, especialmente a partir do processo industrialista do século XVIII, se caracterizam pela ditadura do modo-de-sertrabalho como intervenção, produção e dominação. O trabalho não é mais relacionado com a natureza (modelação) mas com o capital (...) A ditadura do modo-de-ser-trabalho-dominação ta atualmente conduzindo a humanidade a um impasse crucial: ou pomos limites à voracidade produtivista associando trabalho e cuidado, ou vamos de encontro ao pior (...) O regaste do cuidado não se faz às custas do trabalho e sim mediante uma forma diferente de entender e realizar o trabalho. Para isso o ser humano precisa voltar-se sobre si mesmo e descobrir seu modo-de-ser-cuidado. (Boff, 1999, p.97-99)

Hoje mais do que nunca na historia da humanidade, o individuo pode construir um mundo interior com a intermediação dos protocolos de customização dos MP4, Facebook, Orkut, Blog, Web site, Blackberry, jogos de rede. Escolha de imagens, musicas, cores, personagens e formatos que dão forma ao perfil do usuário, dando-lhe uma sensação de ser-único. Preso em uma rede de informações, distrações e testes de pseudo habilidadade, o individuo erra dentro de um labirinto pavimentado pelo poder de escolha.

Paradoxo como possa parecer, é o atual mundo virtual que da ao individuo acesso à sua interioridade. É emblemático o numero de horas dispensado ao mundo da informática e do entretenimento como via de acesso a um pseudo mundo interior. Certamente você já presenciou um exemplo do recente fenômeno de mediatização da experiência. Observe o que acontece em uma festa, um evento ou um passeio: os participantes passam mais tempo a tirar fotos do que a viver a experiência tal como ela se apresenta. Depois de passado o evento, enviam-se mutuamente as fotos por e-mail, recordando dos momentos que não viveram.

Você certamente usa água todos os dias para fazer o café, lavar roupas, a louça, tomar banho. Em seu cotidiano, a água é uma utilidade. No entanto, quando você tira férias, pode ser que você se encontre 
diante do mar ou de um rio. Nesse momento, você se da o tempo de observar a água: sua temperatura, as formas, as cores, a força e velocidade de seu movimento e a sensação da água sobre sua pele, a textura da agua dentro de sua garganta. A água era até então um dos múltiplos confortos que você tinha em casa. Mas, agora ela tornou-se uma porta para o mundo da percepção. Do perceber as belezas da água, um sentimento de reverência começa a emergir.

O cuidado é filho da reverência e do sentimento de valor. É somente através do valor da vida que podemos cultivar a tecnologia interna. É a visão de um continuum entre eu e o vasto-fora-de-mim que permite o acesso a uma tecnologia interna de autoregulação. Tal como indica Boff, o cuidado implica proximidade, intimidade, respeito. Essa tecnologia homeostatica inerente a todo ser vivo zela pelo equilíbrio entre o individuo e o meio.

Se os mecanismos de autoregulação estão funcionando bem, é possível desconstruir todas as marcas que uma crise de pânico possam ter deixado no corpo. Porém, se os mecanismos de autoregulação não estão funcionando bem, a pessoa tem de recorrer, de tempos em tempos, a medicamentos ou drogas para reduzir os sintomas psicofísicos causados pela crise de pânico. E se os mecanismos de autoregulação estão totalmente desativados, para sobreviver, a pessoa se torna dependente do consumo de medicamentos ou drogas a fim de salvaguardar seu equilíbrio e poder funcionar no dia-a-dia.

Se uma secretaria se queixa de dificuldades em respirar, pode ser que o automatismo de bloqueio da inspiração ou da expiração se solidificou pouco a pouco, no seu ambiente de trabalho. Cada vez que o patrão chamava por ela, insconscientemente ela trancava a respiração, para poder suportar o possível embate com seu patrão sem ceder a seus caprichos, mas temerosa de perder o emprego. Durante meses a secretaria vem sobrevivendo no escritório e garantindo seu pão de cada dia através desse mecanismo de defesa que criam tensões inúteis. Tensões inúteis são construídas no decorrer do tempo por movimentos repetitivos do cotidiano e são sedimentadas pela a atitude da pessoa, ou seja, a maneira com a qual ela se percebe e se porta no mundo. Uma dificuldade em respirar pode ser um reflexo de defesa que foi estabelecido em um momento necessário de nossa vida. Mas, agora, ele se cristalizou, ou seja, se tornou disfuncional. O patrão foi transferido para uma outra filial da empresa, mas a secretaria continuou com a respiração curta, angustiada. Mesmo 
não sendo necessario, ela não consegue livrar-se do "mal-respirar". Hanna (1995) indica que um estado de disfunção do tônus leva a uma amnésia senso-motora:

O meio ambiente e o sociocultural impõem estímulos constantes aos reflexos de sobrevivência. Ao longo do tempo esses reflexos se tornam hábitos. Um reflexo é ao mesmo tempo sensorial e motor e quando ele se torna um hábito, há uma perda tanto de controle na região onde se dá a ação motora quanto da capacidade de sentir. Devemos nos referir a esse estado como uma amnésia senso-motora. $\mathrm{O}$ estresse acumulado causa amnésia senso-motora. Aquilo que descrevemos como sendo efeitos da envelhecimento ("é da idade") são, na verdade, efeitos diretos da amnésia senso-motora. Há uma maneira de se liberar das restrições involuntárias geradas pela amnésia senso-motora: um aprendizado somático que recupera a vitalidade de regiões "desmemoriadas" a partir dos mínimos movimentos ainda existentes nessas regiões.

Mesmo se o mundo "externo" não esta a nosso "favor" nas correntes situações do cotidiano que nos parecem injustas, entendiantes, demasiadamente exigentes ou absurdas, a tecnologia interna é um espaço de liberdade. Por tecnologia interna não queremos dizer que, para manter sua liberdade, uma pessoa deva passar seus dias imaginando uma casinha de campo em meio a pássaros cantantes. De acordo com os princípios de aprendizagem no campo da Educação Somática, compreendemos tecnologia interna como o acesso voluntário que podemos ter aos processos fisiológicos que nos autoregulam. Por exemplo, em uma fila de banco insuportável, posso observar que meu maxilar se fecha, se contrai, as sombrancelhas se crispam e uma sensação de frustração começa a me tomar. A frustração pouco a pouco começa a se tornar mais intensa, à medida em que os meus companheiros de fila se põem a reclamar da falta de funcionários suficientes para atender a uma fila tão grande. Através do que vivi em aulas de Educação Somática, para modular as tensões que começam a se acumular em meu corpo diante da longa espera na fila e da irritabilidade geral dos presentes, lembro-me de respirar, sacudir minha cabeça imperceptivelmente, ancorar meus pés no chão, destravar meu maxilar deixando a boca entreaberta, os lábios úmidos e o olhar periférico, amplo, acima das perturbações da fila. Brinco com meus próprios processos fisiológicos porque sou capaz de 
reconhecer o mal estar que me gera a presente situação e sou capaz de me dirigir intencionalmente ao bem estar que já experimentei nas aulas de Educação Somática.

O conceito de comanda intencional de Goldfarb esclarece as premissas acima:

A comanda intencional, ou seja, a possibilidade de escolher, se fundamenta em um processo de comparação ancorado na faculdade de perceber diferenças. Notaremos que a escolha pressupõe diferença : sem diferença, não ha escolha possivel ${ }^{8}$. (Goldfarb, 2006, p.97)

À medida que uma pessoa refina sua capacidade de sentir(se), mais o corpo se assume como instrumento inteligente, capaz de manejar situações que geram desequilíbrio e neutralizá-las.

\section{Conclusão}

Vimos, através desse artigo, que frequentemente limitamos nosso vocabulário gestual aqueles movimentos que nos trazem o resultado esperado, mesmo se esses movimentos desgastam nossa estrutura e geram dor. Associamos gesto $\mathbf{X}$ à resposta desejada $Y$. Desta forma, terminamos por não ousar gestos diferentes dos habituais, por medo de que as respostas sejam diferentes daquelas desejadas.

O papel do educador somático é o de levar o aluno a melhorar o estado de sua saúde através de uma auto-investigação do movimento de seu corpo. Dentro das aulas, são propostos aos alunos movimentos cuja intenção é a desenvolver sua propriocepção. A partir do sentir emerge o perceber. O aluno se da conta de que sua maneira habitual de mover-se esta ligada à patologia da qual se queixa. Uma vez percebida que a maneira habitual de mover-se causa e mantem uma dor, por exemplo, o aluno entra em um processo de descondicionamento gestual, ou seja, aprende novas maneiras de mover-se que previnam lesão e promovam bem estar.

Uma vez que o aluno permitiu-se entrever a possibilidade de sentir-se diferente do que ele sente habitualmente, ele entra em um processo de busca de sua autenticidade somática. Autenticidade somática é o valor do sentir-se

15 La comande volontaire, c'est-à-dire la possibilite de choisir, se fonde sur um processus de comparaison reposant lui-même sur la faculté de percevoir une différence. On notera que le choix présuppose une différence : sans différence, pas de choix possible. (Goldfarb, 2006, p.97). Tradução da autora. 
único, porém pertencente à família dos seres vivos. Esse valor é sinal de maturação da pessoa humana, que zela por sua aparência e gosta de seu corpo tal como ele é, explorando o potencial criativo de seu próprio organismo: fisiologia, sensação, sentimento, pensamento, percepção...

A esse processo denominamos tecnologia interna: o uso intencional dos mecanismos de autoregulação. $\mathrm{O}$ aprendizado do estado de bem estar vivido em aulas de Educação Somática é transferido para situações que acontecem fora da sala de aula: testemunho um possível desequilíbrio se instalar e comando intencionalmente o reequilibrio usando recursos de meu próprio soma.

\section{Referências}

BOIS, D. (2008) Prefácio do livro Em Pleno Corpo: educação somática, movimento e saúde, org. Débora Pereira Bolsanello. Editora Juruá.

BOFF, L. (1999) Saber cuidar : ética do humano, compaixão pela terra. Rio de Janeiro: Editora Vozes.

BRENNAN, R. (2006). La technique Alexander: maîtriser votre posture et votre vie. Les Éditions de I'Homme. Paris.
JOHNSON, D. (org.). (1995) Bone, breath and gesture: practices of embodiment. California: North Atlantic books.

GOLDFARB, L. (1998) Articuler le changement: La Méthode Feldenkrais pour l'éducation du movement. Ed. Espace du Temps Présent. Paris.

GOMEZ, N. (1997) Modular el cuerpo-mente con los balones inflables: enfoque Soma-ritmos. Texto inédito. Costa Rica.

HABIB, Ana Lucia C. M. da Costa. (2001) Uma interpretação de consciência corporal como valor humano em um contexto de educação e reeducação postural. Dissertação para obtenção do titulo de Mestre em Ciências da Motricidade Humana. Inédito. Universidade Castelo Branco. Rio de Janeiro. Copia gentilmente cedida pela autora.

HANNA, Thomas. What is Somatics? Somatics, New York, n.2, vol.14, n² 2, p. 50, 2003. HARTLEY, L. (1995) Wisdom of the Body Moving: An Introduction to Body-Mind Centering ${ }^{\circledR}$. California: North Atlantic Books. 


\section{ABSTRACT}

Somatic Education is a practical and theoretical field made up of different methods that work on the body awareness as a path of transforming a person's mechanical, physiological, neurological and psychological conditions. We present here three concepts from which one can identify the field of Somatic Education as well as understand its proposals in a class: the dis-conditionning of movements, the development of somatic authenticity and the discovery of internal technology. Somatic Education's practices and researches are based on self-investigation of one's own movements; the learning of new ways of moving that can prevent lesions and the intentional use of autoregulation mechanisms.

Key-words: somatic education, psychosomatic, body image, autoregulation, alternative approaches.

Recebido: março/2010.

Aprovado: abril/2011. 